OPEN ACCESS

Edited by:

Mark Slifstein,

Stony Brook University, United States

Reviewed by:

Lihua Qiu,

Second People's Hospital of

Yibin, China

Suhua Chang,

Peking University Sixth Hospital, China

${ }^{*}$ Correspondence:

Ling Hu

1092737313@qq.com; dong_meixue@whu.edu.cn

Specialty section:

This article was submitted to

Brain Imaging Methods,

a section of the journal

Frontiers in Neuroscience

Received: 21 September 2020

Accepted: 30 October 2020

Published: 03 December 2020

Citation:

Dong M-X, Chen G-H and Hu L (2020)

Dopaminergic System Alteration in Anxiety and Compulsive Disorders: A

Systematic Review of Neuroimaging

Studies. Front. Neurosci. 14:608520.

doi: $10.3389 /$ fnins. 2020.608520

\section{Dopaminergic System Alteration in Anxiety and Compulsive Disorders: A Systematic Review of Neuroimaging Studies}

\author{
Mei-Xue Dong ${ }^{1}$, Guang-Hui Chen ${ }^{2}$ and Ling $\mathrm{Hu}^{1 *}$ \\ ${ }^{1}$ Department of Neurology, Hubei General Hospital, Renmin Hospital of Wuhan University, Wuhan, China, ${ }^{2}$ Department of \\ Pharmacy, Hubei General Hospital, Renmin Hospital of Wuhan University, Wuhan, China
}

Objective: The dopaminergic system is involved in many psychiatric disorders as a GABAergic, serotonergic, and glutamatergic system. A systematic review and meta-analysis was performed to elucidate the alteration of the dopaminergic system in anxiety and compulsive disorders.

Methods: The databases of Pubmed, Embase, and ScienceDirect were searched and articles reporting the involvement of the dopaminergic system in patients with anxiety disorder and obsessive compulsive disorder (OCD) were recognized. The key research data were extracted from the included articles and standardized mean differences were calculated using meta-analyses if there were more than two studies with obtainable data. Sensitivity analyses were further performed to detect the stability of results, and the qualities of all the included studies were assessed using the Newcastle Ottawa scale.

Results: Finally, we identified 8 and 11 studies associated with anxiety disorder and OCD for further analysis, respectively. Most consistently, the striatal dopamine $D_{2}$ receptor $\left(D_{2} R\right)$ of OCD patients had decreased while no significant correlation was found between striatal D2R and disease severity. The striatal dopamine transporter (DAT) had not been significantly altered in both the anxiety disorder and OCD patients. The heterogeneity values from the meta-analyses were extremely high while those results remained stable after sensitivity analyses. Inconsistent data were found in the striatal $D_{2} R$ of patients with anxiety disorder. Limited data had suggested that dopamine synthesis increased in most regions of the cerebral cortex and cerebellum in OCD patients.

Conclusions: The most convincing finding was that the $\mathrm{D}_{2}$ receptor decreased in patients with obsessive compulsive disorder. The dopamine transporter may have no relationship with anxiety and compulsive disorder.

Keywords: anxiety, obsessive compulsive disorder, systematic review, dopamine, neuroimaging 


\section{INTRODUCTION}

Anxiety and compulsive disorder has been recognized as one of the most prevalent psychiatric disorders in the Chinese mainland and its prevalence has ranged from 24.47 to $41.12 \%$ (Guo et al., 2016). This broad-spectrum disorder includes generalized anxiety disorder (GAD), non-specific anxiety disorder, panic disorder with or without agoraphobia, social anxiety disorder (SAD), specific phobia, post traumatic stress disorder (PTSD), and obsessive compulsive disorder (OCD) according to the former diagnostic criteria, while OCD and PTSD have been listed as independent diseases according to the recent Diagnostic and Statistical Manual of Mental Disorders, version V (DSM-V).

Various neurotransmitters have been implicated in the pathophysiology of anxiety and compulsive disorder including dopamine (Plavén Sigray et al., 2016), serotonin (Nikolaus et al., 2016), glutamate (Spencer et al., 2014), and $\gamma$-aminobutyric acid (GABA) (Mohler, 2012). A meta-analysis of ${ }^{1} \mathrm{H}$ magnetic resonance spectroscopy (MRS) reported that no significant differences in GABA levels were found in panic disorder patients (Schür et al., 2016) while the GABA(A) receptor was reported to decrease throughout the mesolimbocortical system in anxiety disorder (Nikolaus et al., 2014). Another systematic review found that patients with anxiety-related disorder displayed a significant reduction in the serotonin transporter in the thalamus, amygdala, and hippocampus, reductions of $5-\mathrm{HT}_{1 \mathrm{~A}}$ receptors in the frontal cortex, cingulate, midbrain, hippocampus, amygdala, and insula, and a significant elevation of $5-\mathrm{HT}_{2} \mathrm{~A}$ receptors in the temporal cortex (Nikolaus et al., 2016). The increase of striatal Glx (combination of glutamate, glutamine, and GABA) in OCD patients was also concluded in a review (Naaijen et al., 2015).

There is sufficient evidence for the involvement of the dopaminergic system in psychiatric disorders such as schizophrenia (Horga et al., 2016), major depression disorder (Wooten et al., 2015), bipolar disorder (Yatham et al., 2002), attention deficit hyperactive disorder (ADHD) (Badgaiyan, 2016), anorexia nervosa (Broft et al., 2015), Tourette syndrome (Steeves et al., 2010), and autism (Nakamura et al., 2010). Dopamine is an important neurotransmitter in the central nervous system and is known to regulate human emotions and cognitive abilities, including feeling, thinking, understanding, and reasoning in physiological processes (Pine et al., 2010). A variety of approaches have been applied to determine the role of the dopaminergic system in the brain, however, positron emission tomography (PET) and single photon emission computed tomography (SPECT) are the only methods used to explore the dopaminergic system directly in vivo. We can now assess dopamine synthesis, release, synaptic vesicular transporters, dopaminergic receptors, and DAT in vivo using PET or SPECT with a radiotracer such as $\left[{ }^{18} \mathrm{~F}\right]-\mathrm{DOPA},\left[{ }^{11} \mathrm{C}\right]-$ DOPA, $\left[{ }^{11} \mathrm{C}\right]-\mathrm{DTBZ},\left[{ }^{123} \mathrm{I}\right]-\mathrm{FP}-\mathrm{CIT},\left[{ }^{123} \mathrm{I}\right]-\beta$-CIT, $\left[{ }^{11} \mathrm{C}\right]-\mathrm{PE} 2 \mathrm{I}$, $\left[{ }^{11} \mathrm{C}\right]-\mathrm{CFT},\left[{ }^{99 \mathrm{~m}} \mathrm{Tc}\right]-\mathrm{TRODAT},\left[{ }^{11} \mathrm{C}\right]-\mathrm{SCH}$ 23390, $\left[{ }^{11} \mathrm{C}\right]-\mathrm{NNC}$ 112, $\left[{ }^{123} \mathrm{I}\right]-\mathrm{IBZM}, \quad\left[{ }^{11} \mathrm{C}\right]-\mathrm{RAC}$, and $\left[{ }^{18} \mathrm{~F}\right]$-fallypride (FusarPoli and Meyer-Lindenberg, 2013). Taking advantage of these examinations, dopaminergic system alteration has been gradually cleared in many psychiatric disorders such as schizophrenia
(Fusar-Poli and Meyer-Lindenberg, 2013), ADHD (Fusar-Poli et al., 2012), and major depression disorder (Li et al., 2015).

We have performed a number of studies on affective diseases and Parkinsonism-related disorders and found that the dopaminergic system might play an important role in anxiety disorders (Dong et al., 2018a,b). Nearly half of patients with Parkinson's disease (PD) suffer serious anxiety disorders while the dopaminergic system is confirmed to be the main pathological footstone of PD. Dopamine agonist pramipexole was also reported to alleviate mood disorder in PD patients. There are a number of studies that have focused on the dopaminergic system in anxiety and compulsive disorder but the results were inconsistent with each other. The lack of conformity and fragmentary nature of these results prompted us to reassess the dopaminergic system in patients with anxiety and compulsive disorder. Thus, we performed this systematic review and metaanalysis to elucidate dopaminergic system alteration in anxiety and compulsive disorder.

\section{METHODS}

We carried out the systematic review and meta-analysis following the guidelines recommended by PRISMA statements and the protocol that has already been registered with PROSPERO (CRD42016046788) (Moher et al., 2010).

\section{Data Sources and Searches}

Pubmed, Embase, and ScienceDirect were searched without restrictions of language, publication type, or publication period. The detailed search strategy is shown in Table 1. Briefly, our search criteria included articles that had words related to each of the following three categories in the title or abstract: (i) anxiety-related disorder or OCD; (ii) DAT, dopamine receptor, dopamine synthesis, or dopamine release; (iii) PET or SPECT in vivo studies. This search retrieved all articles through to August 20, 2020. In addition, a backward search of bibliographic references from the identified articles was performed and articles were examined to verify that all relevant articles were included in this article.

\section{Study Selection}

Each article obtained from the search strategy was then reviewed to determine its inclusion or exclusion according to the following criteria. The included articles should compare related psychiatric patients with healthy controls. In the meanwhile, dopaminergic systems, including dopamine synthesis, dopamine release, dopaminergic receptors, or DAT, should be determined by PET or SPECT in vivo between the two groups. The exclusion criteria were reviews, case reports, protocols, animal studies, repeated reports from the same research group, and any other research purposes.

\section{Data Extraction}

Finally, the included articles were reviewed by two skillful reviewers devoted to psychiatric disorders (MXD and $\mathrm{LH}$ ). We recorded the following variables from each article: article information, characteristics of subjects, diagnostic criteria, 
disease severity scale score, assessment method, reference region, region of interest (ROI), and dopaminergic findings. A third reviewer (GHC) then reviewed all the articles and extracted data to check for any errors. Information regarding the direction and significance of the dopaminergic system (including mean values and standard deviation values) of ROI were then used for further analysis.

\section{Statistical Methods}

A meta-analysis was conducted to merge the effect size together if there were more than two studies with obtainable data. The process of statistical analysis was as described before (Dong et al., 2016). Briefly, standardized mean differences (SMDs) were calculated to assess the changes of each efficacy outcome for continuous measures and combined

TABLE 1 | Search strategy of database.

\begin{tabular}{|c|c|c|}
\hline Data source & Search strategy & Total coun \\
\hline Pubmed & $\begin{array}{l}\text { ((((()(((((()anxiety[Title/Abstract]) OR phobia[Title/Abstract]) OR panic[Title/Abstract]) OR agoraphobia[Title/Abstract]) OR } \\
\text { ptsd[Title/Abstract]) OR gad[Title/Abstract]) OR ocd[Title/Abstract]) OR obsessive compulsive disorder[Title/Abstract]) OR } \\
\text { compulsive[Title/Abstract]) OR impulsive[Title/Abstract])) AND (((dopamine[Title/Abstract]) OR dopaminergic[Title/Abstract]) } \\
\text { OR daergic[Title/Abstract])) AND ((((((spect[Title/Abstract]) OR spet[Title/Abstract]) OR pet[Title/Abstract]) OR positron } \\
\text { emission tomography[Title/Abstract]) OR single photon emission computed tomography[Title/Abstract]) OR single photon } \\
\text { emission tomography[Title/Abstract]) }\end{array}$ & 255 \\
\hline Embase & 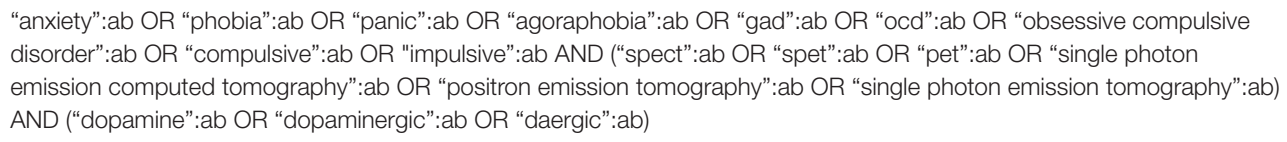 & 446 \\
\hline ScienceDirect & $\begin{array}{l}\text { [abstract (anxiety) or abstract (phobia) or abstract (panic) or abstract (agoraphobia) or abstract (gad) or abstract (ocd) or } \\
\text { abstract (obsessive compulsive disorder) or abstract (compulsive) or abstract (impulsive)] and [abstract (spect) or abstract } \\
\text { (pet) or abstract (spet) or abstract (single photon emission computed tomography) or abstract (positron emission } \\
\text { tomography)] and [abstract (dopamine) or abstract (dopaminergic) or abstract (daergic)] }\end{array}$ & 79 \\
\hline
\end{tabular}

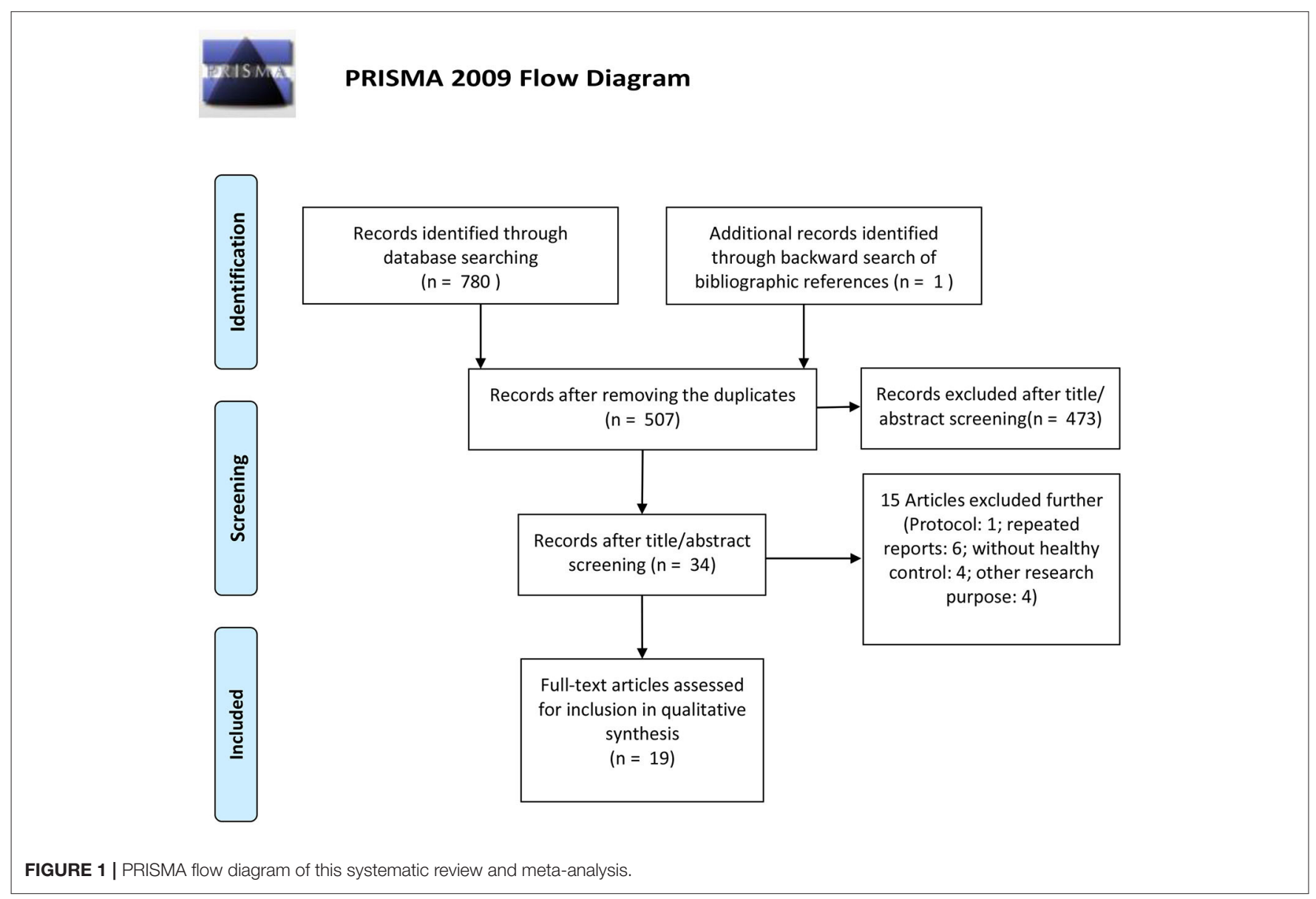


TABLE 2 | Studies assessing dopaminergic system using PET or SPECT in patient with anxiety and compulsive disorder.

\begin{tabular}{llllll}
\hline Study & Subjects & Diagnostic criteria & Method & RR & $\begin{array}{l}\text { Rol } \\
\begin{array}{l}\text { Dopaminergic system } \\
\text { findings }\end{array}\end{array}$
\end{tabular}

\section{Anxiety disorder (8)}

Tiihonen et al. (1997) Finland

\begin{tabular}{|c|c|}
\hline $\begin{array}{l}\text { Van der Wee et al. } \\
(2008)\end{array}$ & $\begin{array}{l}12 \mathrm{SAD} \text { (age } 39.4 \pm 12.6 \\
\text { males); }\end{array}$ \\
\hline Netherlands & $\begin{array}{l}12 \text { controls (age } 33.0 \pm 9 . \\
7 \text { males) }\end{array}$ \\
\hline Maron et al. (2010) & 7 current PD $(35.7 \pm 16$ \\
\hline \multirow[t]{4}{*}{ Estonia } & 0 male); \\
\hline & $7 \mathrm{PD}$ in remission \\
\hline & $(33.4 \pm 14.3,0$ male $)$ \\
\hline & $\begin{array}{l}7 \text { controls }(35.1 \pm 5.3, \\
0 \text { male })\end{array}$ \\
\hline
\end{tabular}

11 SAD (age $40.5 \pm 5.3,3$ males);

28 controls (age

DSM-III-R SAD;

$39.6 \pm 12.3,19$ males)

CGl 5.09 土 0.54;

Drug free

SPECT,

$\left[{ }^{123} \mathrm{I}\right]-\beta-\mathrm{CIT}$

White matter

Striatum

(basal anglia)

DAT decreased in striatum

$(10.05 \pm 1.20$ vs. $11.64 \pm 1.39$,

$p<0.001)$;

No significant correlation

between disease severity and striatal DAT

SPECT, Cerebellum Striatum

LSAS $73.6 \pm 13.7$;

$\left[{ }^{123} \mid\right]-\beta-C I T$

, Drug naïve

DSM-IV PD;

PDSS $(8.9 \pm 2.3)$

Drug free $(>4 \mathrm{~m})$

SPECT,

$\left[{ }^{123} \mid\right]-\beta-C I T$

Cerebellum Striatum
Lee et al. (2015)

China

Hjorth et al. (2019)

Sweden
12 GAD (age $37.1 \pm 12.6,4$ males);

12 controls (age

$37.2 \pm 12.9,4$ males)

$27 \mathrm{SAD}$ (age $31.1 \pm 10.32$

17 males); 43 controls (age

$32.81 \pm 11.56,23$ males)
HAM-A;

Drug free $(>3 \mathrm{~m})$

DSM-IV SAD; LSAS-SR

$84.96 \pm 20.37$; Drug free

(>3m)

\begin{tabular}{|c|c|}
\hline $\begin{array}{l}\text { SPECT, } \\
{\left[{ }^{99 \mathrm{~m}} \mathrm{Tc}\right]-} \\
\text { TRODAT-1 }\end{array}$ & $\begin{array}{l}\text { Occipital } \\
\text { cortex }\end{array}$ \\
\hline $\begin{array}{l}\text { PET, } \\
{\left[{ }^{11} \mathrm{C}\right]-\mathrm{PE} 2 \mathrm{l}}\end{array}$ & $\begin{array}{l}\text { Cerebellar } \\
\text { gray matter }\end{array}$ \\
\hline
\end{tabular}

SPECT,

$\left[{ }^{123} \mid\right]-\beta-C \mid T$

PET,

$\left[{ }^{11} \mathrm{C}\right]-\mathrm{RAC}$;

region

America

DSM-IV SAD;

12 controls (age $30.9 \pm 8.1$ )
Drug free (several months)

Schneier et al. (2000)

America

10 SAD (age $32.5 \pm 10.4,5$

males);

10 controls (age matched)

LSAS

Drug free $(>1 \mathrm{y})$

DSM-IV SAD; LSAS-SR

$63.73 \pm 10.48$; Drug free

$33.82 \pm 11.55)$

16 controls (age 37.82
(2017)

Sweden $\pm 15.22)$
SPCET, Occipital Striatum

$\left[{ }^{123} \mathrm{I}\right]-$ IBZM region

PET,

$\left[{ }^{11} \mathrm{C}\right]-F L B 457$

Cerebellum

Lateral
Occipital Striatum

prefrontal

cortex, medial

frontal cortex, orbitofrontal

cortex,

anterior

cingulated

cortex, insula,

amygdala,

hippocampus
DAT increased in striatum

(7.30 \pm 0.98 vs. $5.47 \pm 1.37$,

$p=0.011)$;

No significant correlation

between LSAS score and striatal DAT

DAT increased in striatum of remitted $\mathrm{PD}(2.72 \pm 0.27$, $p=0.04$ ), didn't change in striatum of current PD compared with control $(2.21 \pm 0.29$ vs. $2.43 \pm 0.17, p=0.12)$; There was an inverse relationship between striatal DAT in total group and the PDSS score, no correlation exist between these two subgroups

DAT decreased in striatum $(1.53 \pm 0.46$ vs. $2.01 \pm 0.31$, $p=0.004)$

DAT increased in amygdala, hippocampus, caudate, and putamen; There was a positive correlation between disease severity and DAT availability in the amygdala, hippocampus, and putamen

DAT did not differ in striatum (7.69 \pm 1.12 vs. $7.62 \pm 0.91$, $p=0.87), D_{2} R$ did not differ at baseline (13.0 \pm 3.7 vs. $13.8 \pm 3.2, p=0.58)$; No significant correlation between LSAS score and striatal DAT,

$D_{2} R$ and dopamine release

$D_{2} R$ decreased in striatum (93.6 \pm 29.8 vs. $133.5 \pm 38.2$, $p=0.02$;

No significant correlation between LSAS score and striatal $D_{2} R$

$D_{2} R$ increased in the orbitofrontal cortex (0.99 \pm 0.28 vs.

$0.76 \pm 0.27, p=0.03)$, no significant differences in the other regions; There was a positive correlation between LSAS-SR summed scores and orbitofrontal cortex $D_{2} R$ 
TABLE 2 | Continued

\begin{tabular}{llllll}
\hline Study Subjects & Diagnostic criteria & Method & RR & Rol & $\begin{array}{l}\text { Dopaminergic system } \\
\text { findings }\end{array}$
\end{tabular}

\section{Obsessive compulsive disorder (11)}

Kim et al. (2003)

South Korea

15 OCD (age

$28.53 \pm 10.91,11$ males);

19 controls (age

$30.53 \pm 8.82,11$ males)

DSM-IV-Korean version;

Y-BOCS $15.27 \pm 3.86$

Drug free $(>4 w)$

SPECT,

[123]-IPT

Occipital

cortex Striatum
(basal ganglia)

DAT increased in the right basal

ganglia (6.84 \pm 2.82 vs.

$4.61 \pm 1.06, p=0.009$ ) while it

tends to increase in the left basal ganglia (6.74 \pm 3.36 vs. $4.85 \pm 1.13, p=0.06)$; No significant correlation between Y-BOCS score and striatal DAT

Van der Wee et al. (2004)

Netherlands
15 OCD (age 31.4 \pm 9.0, 11 DSM-IV: males);

15 controls (age $32.0 \pm 9.5$, Drug naiive 11 males)

\begin{tabular}{|c|c|}
\hline $\begin{array}{l}\text { SPECT, } \\
\left.\left[{ }^{123}\right]\right]-\beta-C I T\end{array}$ & Cerebellum \\
\hline
\end{tabular}

SPECT,

[123I]- $\beta-\mathrm{CIT}$ Y-BOCS (25.3 \pm 8.8$)$; Drug naïve
Occipital Striatum

cortex Thalamus

Midbrain

Brainstem
Hesse et al. (2005) Germany
$15 \mathrm{OCD}$ males);

10 controls

7 males)
SPECT,

${ }^{[99 \mathrm{~m} T \mathrm{TC}}$ -

TRODAT-1

Y-BOCS;

Drug naive

Australia
7 OCD

7 controls (

4 males)
DSM-IV;

Y-BOCS $22.1 \pm 7.6$

PET, $\left[{ }^{11} \mathrm{C}\right]-$

$\mathrm{SCH} 23390$

Cerebellum

(age $40.3 \pm 12.3$, Drug free $(>10 \mathrm{~d})$

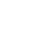

Olver et al. (2010)

Australia
7 OCD (age $40.0 \pm 13.9,4 \quad$ DSM-IV;

$2.1 \pm 7.6$

7 controls (age $40.3 \pm 12.3$, Drug free $(>10 \mathrm{~d}$ )

4 males)
PET, $\left[{ }^{11} \mathrm{C}\right]-$

SCH23390

Cerebellum

Anterior

cingulate cortex

SPECT,

[23I]-IBZM
Cerebellum Striatum

(caudate, putamen)
DAT increased in left caudate (6.80 \pm 0.64 vs. $5.99 \pm 0.78$, $p=0.004)$, right caudate $(6.78 \pm 0.67$ vs. $6.16 \pm 0.85$, $p=0.04)$, left putamen (8.00 \pm 0.74 vs. $7.04 \pm 0.79$, $p=0.006)$, and right putamen (7.97 \pm 0.89 vs. $7.16 \pm 1.23$, $p=0.05)$; No significant correlation between DAT and Y-BOCS score

DAT decreased in striatum (13.2 \pm 1.6 vs. $14.9 \pm 3.3$, $p=0.001$ ),

thalamus/hypothalamus ( $4.2 \pm 0.9$ vs. $4.9 \pm 0.8$ $p=0.026)$, midbrain $(2.5 \pm 0.6$ vs. $3.3 \pm 0.8, p=0.008)$, and brainstem ( $1.7 \pm 0.6$ vs. $2.4 \pm 0.7, p=0.014)$; No significant correlation between DAT and Y-BOCS score

DAT decreased in the right anterior putamen $(2.05 \pm 0.36$ vs. $2.24 \pm 0.37, p=0.031$ ) and a statistical tendency in the left anterior putamen $(2.04 \pm 0.40$ vs. $2.27 \pm 0.55, p=0.071$ )

$D_{1} R$ decreased in caudate compared with controls $(0.59 \pm 0.06$ vs. $0.88 \pm 0.06, p$ $<0.05$ ), and it also decreased in putamen $(0.89 \pm 0.06$ vs. $1.14 \pm 0.06, p<0.05$ ); No significant correlations between $D_{1} R$ and $Y$-BOCS score

$D_{1} R$ decreased in left anterior cingulate compared with controls $(0.14 \pm 0.04$ vs. $0.29 \pm 0.01, p$ $<0.05)$, and it also decreased in the right $(0.13 \pm 0.03 \mathrm{vs}$. $0.25 \pm 0.02, p<0.05)$; High negative correlations were found between $D_{1} R$ score and $Y$-BOCS total score

$D_{2} R$ decreased in left caudate nucleus $(p=0.016)$ while it decreased not significantly in right caudate, left and right putamen; No significant correlation between $\mathrm{Y}$-BOCS score and $D_{2} R$ 
TABLE 2 | Continued

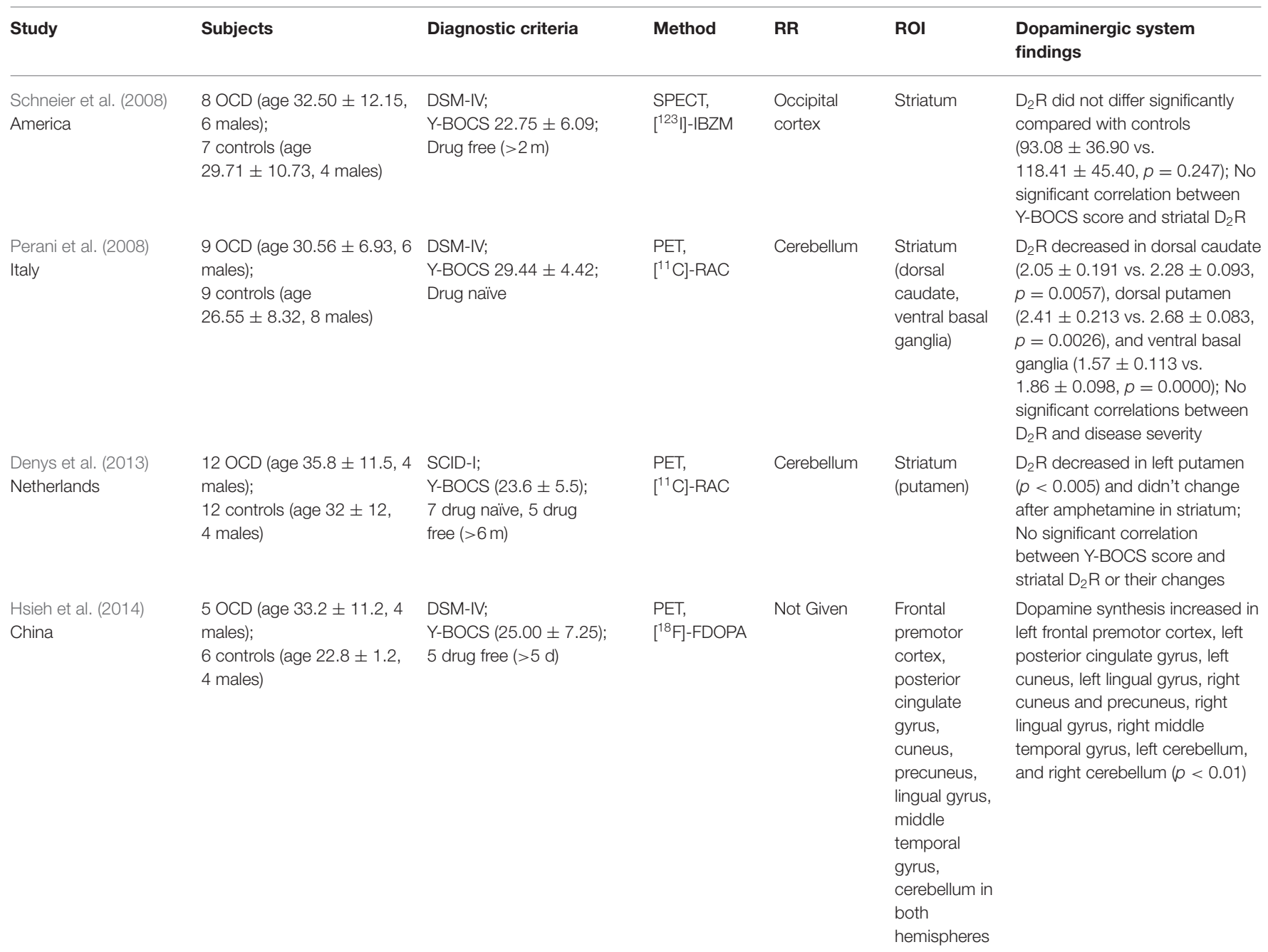

PET, positron emission tomography; SPECT, single photon emission computed tomography; RR, reference region; ROI, region of interest; SAD, social anxiety disorder; DSM, Diagnostic and Statistical manual of Mental disorders; CGI, Clinical Global Impression scale; DAT, dopamine transporter; MRI, magnetic resonance imaging; LSAS, Liebowitz Social anxiety scale; GAD, generalized anxiety disorder; HAM-A, Hamilton Anxiety Rating Scale; $D_{2} R$, dopamine $D_{2}$ receptor; PD, panic disorder; PDSS, Panic Disorder Severity Scale; OCD, obsessivecompulsive disorder; $D_{1} R$, dopamine $D_{1}$ receptor; SCID-I, Structural Clinical Interview for DSM-IV axis I disorders; Y-BOCS, Yale-Brown Obsessive Compulsive Scale; ICD, International Classification of Disease.

into a pooled SMD. If data were measured several times in different parts of the same brain region in one individual, a weighted average and standard deviation were calculated according to the following formulas merged $\mathrm{N}=\frac{\mathrm{N}_{1}+\mathrm{N}_{2}}{2}$, merged mean $=\frac{\mathrm{N}_{1} \mathrm{M}_{1}+\mathrm{N}_{2} \mathrm{M}_{2}}{\mathrm{~N}_{1}+\mathrm{N}_{2}}$, and merged standard deviation $=$ $\sqrt{\begin{array}{l}\left(\left(\mathrm{N}_{1}-1\right) \mathrm{SD}_{1}^{2}+\left(\mathrm{N}_{2}-1\right) \mathrm{SD}_{2}^{2}\right. \\ \left.\left.+\frac{N_{1} N_{2}}{\left(N_{1}+N_{2}\right)\left(M_{1}^{2}+M_{2}^{2}-2 M_{1} M_{2}\right)}\right)\right) /\left(N_{1}+N_{2}-1\right)\end{array}}$

Heterogeneity across studies was assessed using $\mathrm{Chi}^{2}$ test and expressed using $I^{2}$ statistic values. An $I^{2}$ of $<25 \%$, $<50 \%, \quad<75 \%$, and $\geq 75 \%$ represented low, moderate, high, and extremely high heterogeneity, respectively. Sensitivity analyses were conducted using the leave-one-out method. Data were analyzed using RevMan5.4 (Cochrane Information Management System).

\section{RESULTS}

\section{Literature Search Results}

The detailed flowchart of the study selection is shown in Figure 1. A total of 781 records were initially identified and 507 records were left after duplicate records were removed; of these, 473 records were then excluded by title/abstract screening. Of the 34 remaining relevant records, 15 records were further excluded as they were protocol reports, repeated reports from the same research team, a study without healthy controls, or had another research purpose. Thus, 19 studies were finally included in this review (Tiihonen et al., 1997; Schneier et al., 2000, 2008, 2009; Kim et al., 2003; Denys et al., 2004, 2013; Van der Wee et al., 2004, 2008; Hesse et al., 2005; Perani et al., 2008; Olver et al., 2009, 2010; Maron et al., 2010; Hoexter et al., 2013; Hsieh et al., 2014; Lee et al., 2015; Plavén-Sigray et al., 2017; Hjorth et al., 
TABLE 3 | Newcastle Ottawa scales of the included studies.

\begin{tabular}{|c|c|c|c|c|c|c|c|c|c|}
\hline \multirow[t]{2}{*}{ Author } & \multirow[t]{2}{*}{ Year } & \multicolumn{4}{|c|}{ Selection } & \multirow[t]{2}{*}{ Comparability } & \multicolumn{2}{|c|}{ Exposure } & \multirow[t]{2}{*}{ Tota } \\
\hline & & 1 & 2 & 3 & 4 & & 1 & 2 & \\
\hline Tiihonen & 1997 & 1 & 0 & 0 & 1 & 2 & 0 & 1 & 5 \\
\hline Wee & 2008 & 1 & 0 & 1 & 1 & 2 & 0 & 1 & 6 \\
\hline Schneier & 2009 & 1 & 0 & 1 & 1 & 2 & 0 & 1 & 6 \\
\hline Schneier & 2000 & 1 & 0 & 1 & 1 & 2 & 0 & 1 & 6 \\
\hline Sigray & 2017 & 1 & 0 & 1 & 1 & 2 & 0 & 1 & 6 \\
\hline Lee & 2015 & 1 & 0 & 1 & 1 & 2 & 0 & 1 & 6 \\
\hline Maron & 2010 & 0 & 0 & 0 & 1 & 2 & 0 & 1 & 4 \\
\hline Kim & 2003 & 1 & 0 & 0 & 1 & 1 & 0 & 1 & 4 \\
\hline Wee & 2004 & 1 & 1 & 1 & 1 & 2 & 0 & 1 & 7 \\
\hline Hesse & 2005 & 1 & 0 & 1 & 1 & 1 & 0 & 1 & 5 \\
\hline Hoexter & 2013 & 0 & 0 & 0 & 1 & 1 & 0 & 1 & 3 \\
\hline Olver & 2009 & 1 & 0 & 0 & 1 & 2 & 0 & 1 & 5 \\
\hline Olver & 2010 & 1 & 0 & 0 & 1 & 2 & 0 & 1 & 5 \\
\hline Denys & 2004 & 1 & 0 & 1 & 1 & 2 & 0 & 1 & 6 \\
\hline Schneier & 2008 & 1 & 0 & 1 & 1 & 2 & 0 & 1 & 6 \\
\hline Perani & 2008 & 1 & 1 & 1 & 1 & 1 & 0 & 1 & 6 \\
\hline Denys & 2013 & 1 & 0 & 1 & 1 & 1 & 0 & 1 & 5 \\
\hline Hsieh & 2014 & 1 & 0 & 0 & 1 & 2 & 0 & 1 & 5 \\
\hline Hjorth & 2019 & 1 & 0 & 1 & 1 & 2 & 0 & 1 & 6 \\
\hline
\end{tabular}

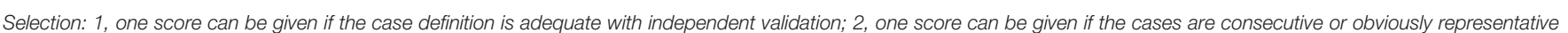

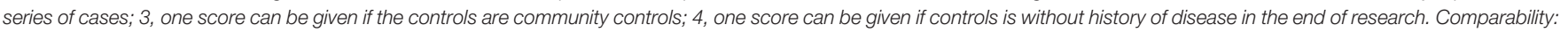

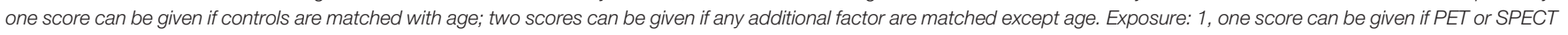
are assessed blindly for investigators; 2, one score can be given if same method of ascertainment is for cases and controls.

2019). We then aggregated these studies by psychiatric disorders, including anxiety disorder and obsessive compulsive disorder. The characteristics of each study are exhibited in Table 2. The Newcastle Ottawa scales of all the included studies are shown in Table 3.

\section{Dopaminergic System in Patients With Anxiety Disorder}

There were a total of eight studies focusing on the dopaminergic system in patients with anxiety disorder. The mean age of subjects ranged from 30 to 40 years old without statistically significant differences, and no specific pattern of age emerged among these studies. Striatal DAT was reported in six studies and the results were different from each other. A meta-analysis was conducted and no statistically positive effect was found as the total pooled SMD was 0.09 [95\% confidence interval (CI), -1.08 to 1.27] (Figure 2A). The heterogeneity was extremely high $\left(I^{2}=89 \%\right)$ while the result remained stable through sensitivity analyses (Table 4). All of them reported no significant correlation between striatal DAT and disease severity. Only one study (Hjorth et al., 2019) assessed an extrastriatal dopamine transporter and found that the increased dopamine transporter in the amygdala and hippocampus was positively correlated with disease severity. Two studies (Schneier et al., 2000, 2009) from the same team determined the striatal dopamine $\mathrm{D}_{2}$ receptor $\left(\mathrm{D}_{2} \mathrm{R}\right)$ using different radiotracers while the results were contradictory. They also found that dopamine release had not changed in anxiety patients (Schneier et al., 2009). Another study (Plavén-Sigray et al., 2017) indicated that $\mathrm{D}_{2} \mathrm{R}$ had increased in the orbitofrontal cortex using a high-affinity $\mathrm{D}_{2} \mathrm{R}$ radiotracer whilst a positive correlation was found between disease severity and orbitofrontal cortex $\mathrm{D}_{2} \mathrm{R}$.

\section{Dopaminergic System in OCD Patients}

A total of 11 studies examined the dopaminergic system in OCD patients. The mean age of OCD patients ranged from 28 to 40 years old, and the controls were age-sex matched with those patients. Striatal DAT was determined in four studies and all the means were merged together using a meta-analysis (Figure $2 \mathbf{B}$ ). The overall result showed no significant change and the total pooled SMD was 0.12 (95\% CI, -0.69 to 0.94$)$. Although the heterogeneity was extremely high $\left(I^{2}=83 \%\right)$, the result remained stable through sensitivity analyses (Table 4). No significant correlation was claimed by these studies between DAT and disease severity. A research team indicated that the dopamine $D_{1}$ receptor $\left(D_{1} R\right)$ had decreased in both the striatum and anterior cingulate cortex separately in two articles (Olver et al., 2009, 2010). High negative correlation was found between the total score of the Yale-Brown Obsessive Compulsive Scale (Y-BOCS) and $D_{1} R$ in the anterior cingulate cortex but not in the striatum. Four studies (Denys et al., 2004, 2013; Perani et al., 2008; Schneier et al., 2008) determined striatal $\mathrm{D}_{2} \mathrm{R}$ but only three studies with obtainable data could be merged using a meta-analysis (Figure 2C). The merged result was statistically significant and 


\section{A Dopamine transporter of anxiety disorder}

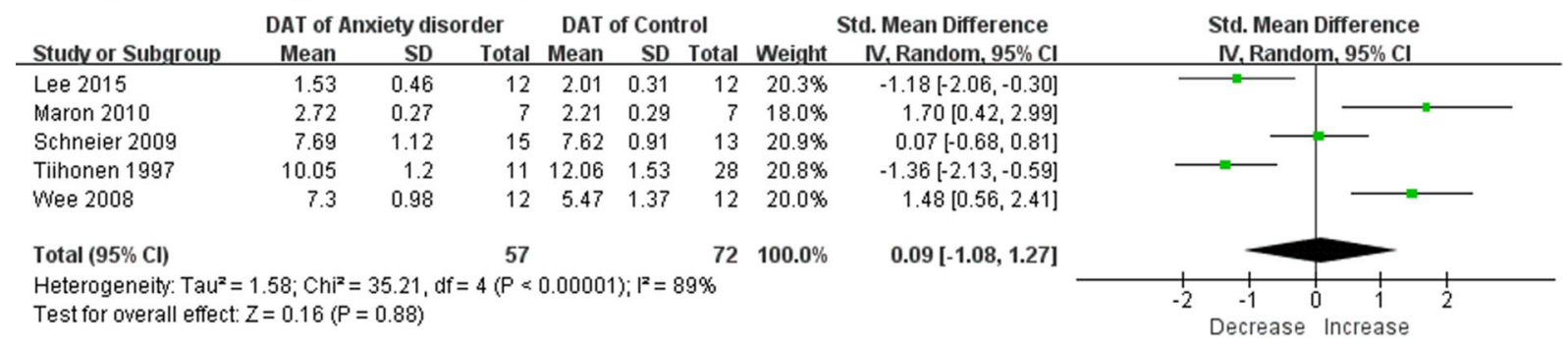

\section{B Dopamine transporter of obsessive compulsive disorder}

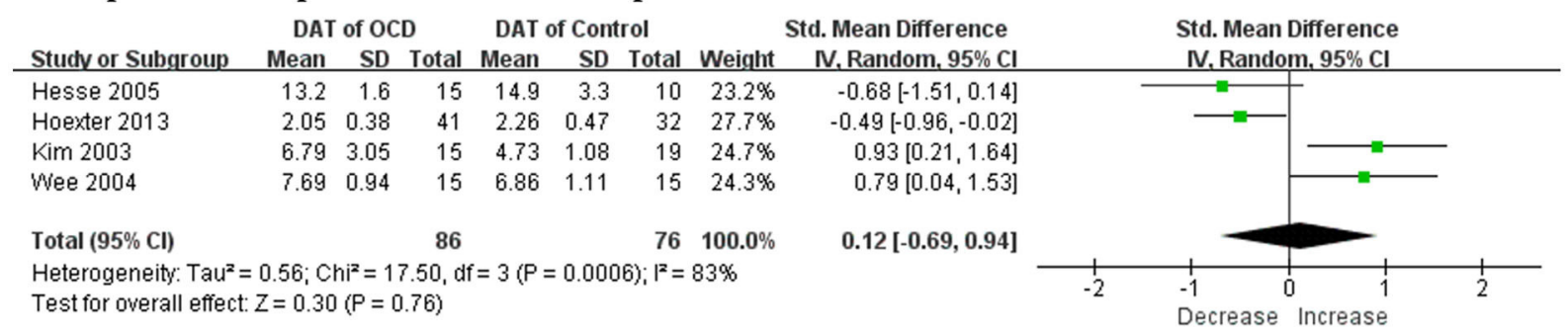

C D2 receptor of obsessive compulsive disorder

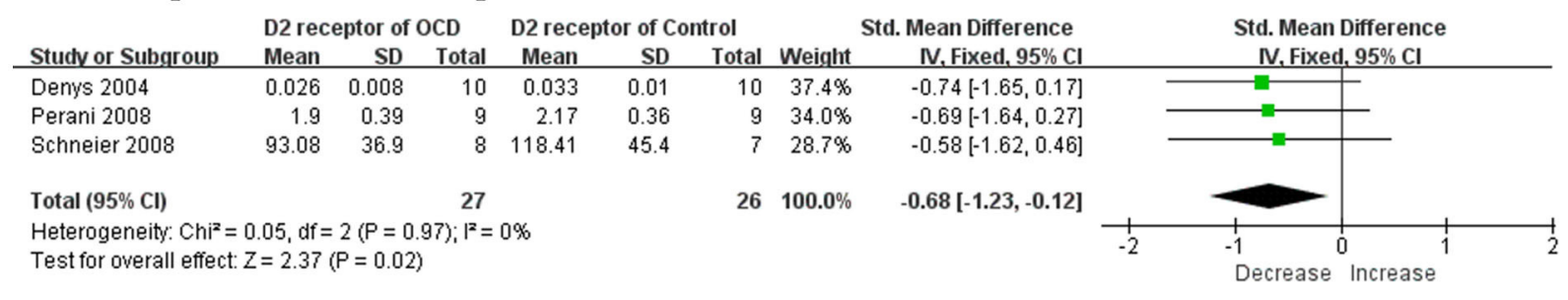

FIGURE 2 | Forest plots of SMDs in the meta-analysis. (A) DAT had not altered in patients with anxiety disorder (95\% Cl of SMD, -1.49 to 1.59) and the heterogeneity was extremely high ( $\left.I^{2}=91 \%\right)$; (B) DAT had not altered in OCD patient ( $95 \% \mathrm{Cl}$ of SMD, -0.69 to 0.94$)$ while the heterogeneity was extremely high $\left(I^{2}=83 \%\right)$; and $(\mathbf{C})$ dopamine $\mathrm{D}_{2}$ receptors had decreased in OCD patient $(95 \% \mathrm{Cl}$ of $\mathrm{SMD},-1.23$ to -0.12$)$ and the heterogeneity was mild $\left(I^{2}=0 \%\right)$. SMD, standard mean deviation; DAT, dopamine transporter; OCD, obsessive compulsive disorder.

the total SMD was $-0.68(95 \% \mathrm{CI},-1.23$ to -0.12$)$. The heterogeneity was mild $\left(I^{2}=0 \%\right)$ while the result was unstable through sensitivity analyses (Table 4). A study (Denys et al., 2013) that was excluded in the meta-analysis also claimed a decrease of $\mathrm{D}_{2} \mathrm{R}$. Meanwhile, there was no significant correlation between the Y-BOCS score and $\mathrm{D}_{2} \mathrm{R}$. In the meantime, one study (Denys et al., 2013) assessed dopamine release in OCD patients and no changes of $\mathrm{D}_{2} \mathrm{R}$ could be found after an injection of amphetamine in the striatum compared with controls. A study (Hsieh et al., 2014) indicated that dopamine synthesis increased throughout the brain, including the left frontal premotor cortex, left posterior cingulate gyrus, left cuneus, left lingual gyrus, right cuneus and precuneus, right lingual gyrus, right middle temporal gyrus, left cerebellum, and right cerebellum.

\section{DISCUSSION}

The dopaminergic system mainly consists of nigrostriatal, mesocortical, mesolimbic, and tuberoinfundibular pathways
(Hou et al., 2014). Dopamine is synthesized by dopaminergic neurons in the substantia nigra pars compacta, ventral tegmental area, and arcuate and periventricular nucleus of the hypothalamus (Cortes et al., 2016). After being released into the synaptic cleft, it binds with dopamine receptors 15 (mainly D1R and D2R) to exert excitatory or inhibitory signaling. The dopamine in the synaptic cleft can be dissolved by catechol-O-methyltransferase and monoamine, and its level can also be modulated by a dopamine transporter (Figure 3). The involvement of the dopaminergic system in some psychiatric disorders has already been elucidated in detail and might shed light on further drug design strategies (Leggio et al., 2016).

Anxiety and compulsive disorder is among the most common psychiatric disorders, with a lifetime prevalence between 17 and $69 \%$ (Kessler et al., 2007). An ongoing issue is that the disorder is under-diagnosed and most patients never receive any treatment. Currently, diagnosis lacks repeatable and objective evidence, and is mainly dependent on the professional skills of psychiatrists and some clinical psychiatric scales. Serotonin reuptake inhibitors 
and serotonin norepinephrine reuptake inhibitors are usually used as part of the preferred initial treatment (Katzman et al., 2014) with response rates in the range of $30-50 \%$ (Reinhold and Rickels, 2015). We have performed a number of studies about this issue before (Dong et al., 2017a,b; Dong et al., 2018a; Chen et al., 2020; Hu et al., 2020). The main aim of this study was to assess whether dopaminergic dysregulation can be detected in anxiety and obsessive disorder with any degree of consistency and specificity. We hope to elucidate the mechanisms of these disorders for clinical diagnosis and further drug development.

Overall, the available studies were quite heterogeneous and often contradictory. Eight studies provided evidence of the

TABLE 4 | The results of sensitivity analyses after omitting each study.

\begin{tabular}{lcccc}
\hline Study omitted & SMD & Lower limit & Upper limit & $\boldsymbol{p}$ value \\
\hline DAT of anxiety disorder & & & & \\
Lee et al. (2015) & 0.42 & -0.96 & 1.80 & 0.55 \\
Maron et al. (2010) & -0.26 & -1.48 & 0.96 & 0.68 \\
Schneier et al. (2009) & 0.12 & -1.47 & 1.71 & 0.88 \\
Tiihonen et al. (1997) & 0.47 & -0.79 & 1.74 & 0.46 \\
Van der Wee et al. (2008) & -0.27 & -1.43 & 0.89 & 0.65 \\
DAT of obsessive compulsive disorder & & & \\
Hesse et al. (2005) & 0.37 & -0.62 & 1.36 & 0.46 \\
Hoexter et al. (2013) & 0.36 & -0.61 & 1.33 & 0.46 \\
Kim et al. (2003) & -0.14 & -0.98 & 0.70 & 0.74 \\
Van der Wee et al. (2004) & -0.09 & -1.03 & 0.86 & 0.86 \\
D2R of obsessive compulsive disorder & & & \\
Denys et al. (2004) & -0.64 & -1.34 & 0.07 & 0.08 \\
Perani et al. (2008) & -0.67 & -1.36 & 0.02 & 0.06 \\
Schneier et al. (2008) & -0.71 & -1.38 & -0.05 & 0.03 \\
\hline
\end{tabular}

$S M D$, standard mean difference; DAT, dopamine transporter; D2R, dopamine D2 receptor. dopaminergic system in anxiety patients and eleven studies focused on OCD patients. In the total 19 studies, 10 studies were about DAT, seven studies were about $\mathrm{D}_{2} \mathrm{R}$, two studies were about $\mathrm{D}_{1} \mathrm{R}$, two studies were about dopamine release, and only one study was about dopamine synthesis.

The alterations of DAT in patients with anxiety disorders were inconsistent with each other, although the same radiotracer and technique were used. In total, no alteration could be found during the meta-analysis. The primary discrepancy between these studies could have been due to their small sample sizes. Other possible reasons may be the methodological differences. Two studies administered the serotonin reuptake inhibitors citalopram (Tiihonen et al., 1997) or paroxetine (Van der Wee et al., 2008) to block [123I]- $\beta$-CIT from binding to serotonin transporters before a SPECT scan while another study did not (Schneier et al., 2009). Reference regions were different as well, including white matter, the cerebellum, and the occipital region. Structural MRI was also used to accurately identify regions of interest in a study (Van der Wee et al., 2008). All of these may partly explain the extremely high heterogeneity of striatal DAT. A recent study from Hjorth using PET (Hjorth et al., 2019) claimed that DAT of the amygdala and hippocampus had increased in 27 anxiety patients. Striatal $\mathrm{D}_{2} \mathrm{R}$ binding significantly decreased in a study using SPECT (Schneier et al., 2000), however, the result had changed when using another radiotracer (Schneier et al., 2009) performed by the same team. The researchers themselves mainly attributed it to the small sample size and not to methodological difference. They also did not find any change in dopamine release after an amphetamine injection. A recent study (Plavén Sigray et al., 2016) using PET with [ $\left.{ }^{11} \mathrm{C}\right]-\mathrm{FLB} 457$ as the radiotracer found $\mathrm{D}_{2} \mathrm{R}$ had increased in the orbitofrontal cortex. However, this finding did not survive after correction for multiple comparisons. In short, no reliable evidence can confirm that the dopaminergic system has participated in anxiety disorders.
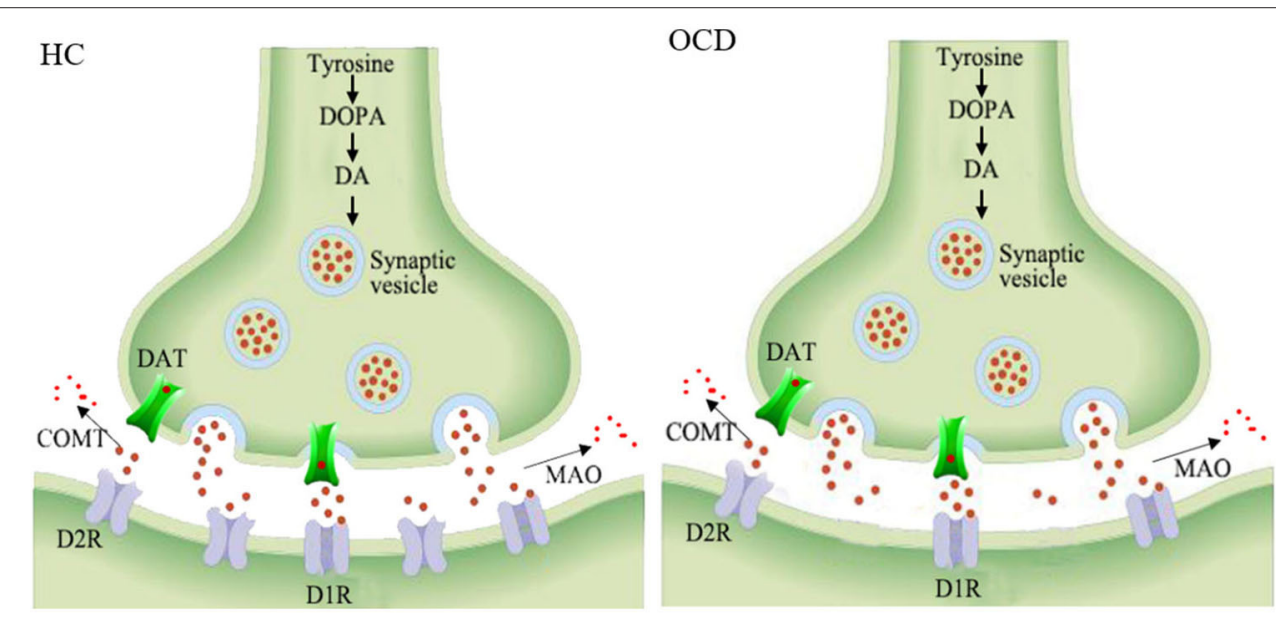

FIGURE 3 | Schematic representation of the decreased striatal D2 receptors in the synapses of OCD patients. HC, healthy control; OCD, obsessive compulsive disorder; DOPA, dioxyphenylalanine; DA, dopamine; DAT, dopamine transporter; COMT, catechol-o-methyltransferase; MAO, monoamine oxidase; D1R, dopamine receptor 1; D2R, dopamine receptor 2. 
There were a total of four studies focusing on DAT in OCD patients and no alteration of DAT was found in OCD patients using a meta-analysis. $\mathrm{D}_{1} \mathrm{R}$ of $\mathrm{OCD}$ was determined only in two studies from the same team (Olver et al., 2009, 2010). They found that $D_{1} R$ had decreased in the striatum and anterior cingulate cortex. Only seven patients were included in the study so the result needs to be further confirmed. $\mathrm{D}_{2} \mathrm{R}$ had decreased in OCD patients and mild heterogeneity existed. Dopamine release seemed to have no correlation with OCD, either. Only one study (Hsieh et al., 2014) including five patients with OCD determined dopamine synthesis, and it found that dopamine synthesis decreased throughout the brain.

Multiple neurotransmitter systems were involved in the mechanism of OCD according to former studies. It was reported that Glx had decreased in the anterior cingulate cortex while it increased in the caudate using MRS (Brennan et al., 2013; Naaijen et al., 2014). The serotoninergic system had also been significantly altered, as reported in a comparative analysis (Nikolaus et al., 2016). The dopaminergic system may be regulated by the glutamatergic and serotonergic systems (Nikolaus et al., 2010). From this research, we confirmed that striatal $\mathrm{D}_{2} \mathrm{R}$ had decreased in OCD patients. It may be due to receptor internalization, increased levels of endogenous dopamine competing with the radiotracer, or a combination of both (Denys et al., 2013). A dopamine depletion study should be performed to assess whether endogenous dopamine was involved in OCD patients. Currently, serotonin remains the therapeutic target of neurotransmitters and selective serotonin reuptake inhibitors are the first-line drugs to treat OCD patients. However, those drugs can not function well in many patients and induce a number of side effects. Atypical antipsychotics are an important replacement therapy for some OCD patients. These drugs, including risperidone and aripiprazole, can activate $\mathrm{D}_{2} \mathrm{R}$ as well as regulating the serotoninergic system (Stein et al., 2012). Pramipexole, a

\section{REFERENCES}

Badgaiyan, R. (2016). Dynamic molecular imaging guides treatment options for attention deficit hyperactive disorder (ADHD). J. Nuclear Med. 57.

Brennan, B. P., Rauch, S. L., Jensen, J. E., and Pope, H. G. (2013). A critical review of magnetic resonance spectroscopy studies of obsessive-compulsive disorder. Biol. Psychiatry 73, 24-31. doi: 10.1016/j.biopsych.2012.06.023

Broft, A., Slifstein, M., Osborne, J., Kothari, P., Morim, S., Shingleton, R., et al. (2015). Striatal dopamine type 2 receptor availability in anorexia nervosa. Psychiatry Res. 233, 380-387. doi: 10.1016/j.pscychresns.2015.06.013

Chen, G., Wang, Y., Li, Y., Zhang, L., and Dong, M. (2020). A novel hippocampus metabolite signature in diabetes mellitus rat model of diabetic encephalopathy. Metab. Brain Dis. 35, 895-904. doi: 10.1007/s11011-020-00541-2

Cortes, A., Moreno, E., Rodriguez-Ruiz, M., Canela, E. I., and Casado, V. (2016). Targeting the dopamine D3 receptor: an overview of drug design strategies. Expert Opin. Drug Discov. 11, 641-664. doi: 10.1080/17460441.2016.1185413

Denys, D., De Vries, F., Cath, D., Figee, M., Vulink, N., Veltman, D. J., et al. (2013). Dopaminergic activity in Tourette syndrome and obsessivecompulsive disorder. Eur. Neuropsychopharmacol. 23, 1423-1431. doi: 10.1016/j.euroneuro.2013.05.012

Denys, D., Van Der Wee, N., Janssen, J., De Geus, F., and Westenberg, H. G. (2004). Low level of dopaminergic D2 receptor binding in obsessive-compulsive disorder. Biol. Psychiatry 55, 1041-1045. doi: 10.1016/j.biopsych.2004.01.023 dopamine $\mathrm{D}_{2} \mathrm{R}$ agonist widely used in $\mathrm{PD}$ patients, was also reported to be one of the most important drugs for depression in $\mathrm{PD}$ patients. It is worthwhile to explore the usage of these dopamine receptor agonists in OCD patients.

\section{CONCLUSION}

This is the first systematic review and meta-analysis to elucidate the dopaminergic system in anxiety and compulsive disorder. Studies about this issue are limited in number and contradictory. The most convincing finding is that striatal $\mathrm{D}_{2} \mathrm{R}$ was decreased in OCD patients. Dopamine transporters may have no relationship with anxiety and compulsive disorder. The alteration of the dopaminergic system needs to be further confirmed by more repeatable, reliable, and large-sample size research.

\section{DATA AVAILABILITY STATEMENT}

The original contributions presented in the study are included in the article/supplementary material, further inquiries can be directed to the corresponding author/s.

\section{AUTHOR CONTRIBUTIONS}

M-XD and $\mathrm{LH}$ conceived the study. The data analysis was performed by M-XD, G-HC, and LH. The manuscript was revised by $\mathrm{M}-\mathrm{XD}$ and $\mathrm{LH}$. All authors contributed to the article and approved the submitted version.

\section{FUNDING}

This research was supported by the Hubei Provincial Natural Science Foundation of China (2020CFB232) and the Fundamental Research Funds for the Central Universities (2042020kf0056).
Dong, M. X., Feng, X., Xu, X. M., Hu, L., Liu, Y., Jia, S. Y., et al. (2018a). Integrated analysis reveals altered lipid and glucose metabolism and identifies NOTCH2 as a biomarker for Parkinson's disease related depression. Front. Mol. Neurosci. 11:257. doi: 10.3389/fnmol.2018.00257

Dong, M. X., Hu, L., Huang, Y. J., Xu, X. M., Liu, Y., and Wei, Y. D. (2017a). Cerebrovascular risk factors for patients with cerebral watershed infarction: a case-control study based on computed tomography angiography in a population from Southwest China. Medicine 96:e7505. doi: 10.1097/MD.0000000000007505

Dong, M. X., Hu, Q. C., Shen, P., Pan, J. X., Wei, Y. D., Liu, Y. Y., et al. (2016). Recombinant tissue plasminogen activator induces neurological side effects independent on thrombolysis in mechanical animal models of focal cerebral infarction: a systematic review and meta-analysis. PLOS ONE 11:e0158848. doi: 10.1371/journal.pone.0158848

Dong, M. X., Li, C. M., Shen, P., Hu, Q. C., Wei, Y. D., Ren, Y. F., et al. (2018b). Recombinant tissue plasminogen activator induces long-term anxiety-like behaviors via the ERK1/2-GAD1-GABA cascade in the hippocampus of a rat model. Neuropharmacology 128, 119-131. doi: 10.1016/j.neuropharm.2017.09.039

Dong, M. X., Xu, X. M., Hu, L., Liu, Y., Huang, Y. J., and Wei, Y. D. (2017b). Serum butyrylcholinesterase activity: a biomarker for Parkinson's disease and related dementia. Biomed. Res. Int. 2017:1524107. doi: 10.1155/2017/15 24107 
Fusar-Poli, P., and Meyer-Lindenberg, A. (2013). Striatal presynaptic dopamine in schizophrenia, part I: meta-analysis of dopamine active transporter (DAT) density. Schizophr. Bull. 39, 22-32. doi: 10.1093/schbul/sbr111

Fusar-Poli, P., Rubia, K., Rossi, G., Sartori, G., and Balottin, U. (2012). Striatal dopamine transporter alterations in ADHD: pathophysiology or adaptation to psychostimulants? A meta-analysis. Am. J. Psychiatry 169, 264-272. doi: 10.1176/appi.ajp.2011.11060940

Guo, X., Meng, Z., Huang, G., Fan, J., Zhou, W., Ling, W., et al. (2016). Metaanalysis of the prevalence of anxiety disorders in mainland China from 2000 to 2015. Sci. Rep. 6:28033. doi: 10.1038/srep28033

Hesse, S., Muller, U., Lincke, T., Barthel, H., Villmann, T., Angermeyer, M. C., et al. (2005). Serotonin and dopamine transporter imaging in patients with obsessive-compulsive disorder. Psychiatry Res. 140, 63-72. doi: 10.1016/j.pscychresns.2005.07.002

Hjorth, O., Frick, A., Gingnell, M., Hoppe, J., Faria, V., Hultberg, S., et al. (2019). Expression and co-expression of serotonin and dopamine transporters in social anxiety disorder: a multitracer positron emission tomography study. Mol. Psychiatry. doi: 10.1038/s41380-019-0618-7. [Epub ahead of print].

Hoexter, M. Q., Dougherty, D., Shavitt, R. G., Diniz, J. B., Deckersbach, T., Chi, M., et al. (2013). Striatal dopamine transporter availability in obsessivecompulsive disorder: a randomized clinical trial using [TC99 M]-TRODAT-1 SPECT. Neuropsychopharmacology 38, S195-S196.

Horga, G., Cassidy, C. M., Xu, X., Moore, H., Slifstein, M., Van Snellenberg, J. X., et al. (2016). Dopamine-related disruption of functional topography of striatal connections in unmedicated patients with schizophrenia. JAMA Psychiatry 73, 862-870. doi: 10.1001/jamapsychiatry.2016. 0178

Hou, H., Wang, C., Jia, S., Hu, S., and Tian, M. (2014). Brain dopaminergic system changes in drug addiction: a review of positron emission tomography findings. Neurosci. Bull. 30, 765-776. doi: 10.1007/s12264-014-1469-5

Hsieh, H. J., Lue, K. H., Tsai, H. C., Lee, C. C., Chen, S. Y., and Kao, P. F. (2014). L-3,4-Dihydroxy-6-[F-18]fluorophenylalanine positron emission tomography demonstrating dopaminergic system abnormality in the brains of obsessive-compulsive disorder patients. Psychiatry Clin. Neurosci. 68, 292-298. doi: $10.1111 / p c n .12139$

Hu, L., Dong, M., Huang, Y., Lu, C., Qian, Q., Zhang, C., et al. (2020). Integrated metabolomics and proteomics analysis reveals plasma lipid metabolic disturbance in patients with Parkinson's disease. Front. Mol. Neurosci. 13:80. doi: $10.3389 /$ fnmol.2020.00080

Katzman, M. A., Bleau, P., Blier, P., Chokka, P., Kjernisted, K., Van Ameringen, M., et al. (2014). Canadian clinical practice guidelines for the management of anxiety, posttraumatic stress and obsessive-compulsive disorders. $B M C$ Psychiatry 14 (Suppl. 1):S1. doi: 10.1186/1471-244X-14-S1-S1

Kessler, R. C., Angermeyer, M., Anthony, J. C., De Graaf, R. O. N., Demyttenaere, K., Gasquet, I., et al. (2007). Lifetime prevalence and age-of-onset distributions of mental disorders in the World Health Organization's World Mental Health Survey Initiative. World Psychiatry 6, 168-176.

Kim, C. H., Koo, M. S., Cheon, K. A., Ryu, Y. H., Lee, J. D., and Lee, H. S. (2003). Dopamine transporter density of basal ganglia assessed with [123I]IPT SPET in obsessive-compulsive disorder. Eur. J. Nucl. Med. Mol. Imaging 30, 1637-1643. doi: 10.1007/s00259-003-1245-7

Lee, L. T., Tsai, H. C., Chi, M. H., Chang, W. H., Chen, K. C., Lee, I. H., et al. (2015). Lower availability of striatal dopamine transporter in generalized anxiety disorder: a preliminary two-ligand SPECT study. Int. Clin. Psychopharmacol. 30, 175-178. doi: 10.1097/YIC.00000000000 00067

Leggio, G. M., Bucolo, C., Platania, C. B., Salomone, S., and Drago, F. (2016). Current drug treatments targeting dopamine D3 receptor. Pharmacol. Ther. 165, 164-177. doi: 10.1016/j.pharmthera.2016.06.007

Li, Z., He, Y., Tang, J., Zong, X., Hu, M., and Chen, X. (2015). Molecular imaging of striatal dopamine transporters in major depression-a meta-analysis. J. Affect. Disord. 174, 137-143. doi: 10.1016/j.jad.2014.11.045

Maron, E., Nutt, D. J., Kuikka, J., and Tiihonen, J. (2010). Dopamine transporter binding in females with panic disorder may vary with clinical status. J. Psychiatr. Res. 44, 56-59. doi: 10.1016/j.jpsychires.2009.04.014

Moher, D., Liberati, A., Tetzlaff, J., and Altman, D. G. (2010). Preferred reporting items for systematic reviews and meta-analyses: the PRISMA statement. Int. J. Surg. 8, 336-341. doi: 10.1016/j.ijsu.2010.02.007
Mohler, H. (2012). The GABA system in anxiety and depression and its therapeutic potential. Neuropharmacology 62, 42-53. doi: 10.1016/j.neuropharm.2011.08.040

Naaijen, J., Lythgoe, D. J., Amiri, H., Buitelaar, J. K., and Glennon, J. C. (2015). Fronto-striatal glutamatergic compounds in compulsive and impulsive syndromes: a review of magnetic resonance spectroscopy studies. Neurosci. Biobehav. Rev. 52, 74-88. doi: 10.1016/j.neubiorev.2015.02.009

Naaijen, J., Lythgoe, D. J., Buitelaar, J. K., and Glennon, J. C. (2014). Fronto-striatal glutamate in compulsive and impulsive syndromes: a review of MR spectroscopy studies. Eur. Neuropsychopharmacol. 24:S185. doi: 10.1016/S0924-977X(14)70284-6

Nakamura, K., Sekine, Y., Ouchi, Y., Tsujii, M., Yoshikawa, E., Futatsubashi, M., et al. (2010). Brain serotonin and dopamine transporter bindings in adults with high-functioning autism. Arch. Gen. Psychiatry 67, 59-68. doi: 10.1001/archgenpsychiatry.2009.137

Nikolaus, S., Antke, C., Beu, M., and Müller, H. W. (2010). Cortical GABA, striatal dopamine and midbrain serotonin as the key players in compulsive and anxiety disorders-results from in vivo imaging studies. Revi.Neurosci. 21, 119-139. doi: 10.1515/REVNEURO.2010.21.2.119

Nikolaus, S., Hautzel, H., and Müller, H. W. (2014). Focus on GABAA receptor function: a comparative analysis of in vivo imaging studies in neuropsychiatric disorders. Nuklearmedizin 53, 227-237. doi: 10.3413/Nukmed-0647-14-03

Nikolaus, S., Muller, H. W., and Hautzel, H. (2016). Different patterns of 5 HT receptor and transporter dysfunction in neuropsychiatric disorders-a comparative analysis of in vivo imaging findings. Rev. Neurosci. 27, 27-59. doi: 10.1515/revneuro-2015-0014

Olver, J. S., O'keefe, G., Jones, G. R., Burrows, G. D., Tochon-Danguy, H. J., Ackermann, U., et al. (2009). Dopamine D1 receptor binding in the striatum of patients with obsessive-compulsive disorder. J. Affect. Disord. 114, 321-326. doi: 10.1016/j.jad.2008.06.020

Olver, J. S., O'keefe, G., Jones, G. R., Burrows, G. D., Tochon-Danguy, H. J., Ackermann, U., et al. (2010). Dopamine $\mathrm{D}(1)$ receptor binding in the anterior cingulate cortex of patients with obsessive-compulsive disorder. Psychiatry Res. 183, 85-88. doi: 10.1016/j.pscychresns.2010.04.004

Perani, D., Garibotto, V., Gorini, A., Moresco, R. M., Henin, M., Panzacchi, A., et al. (2008). In vivo PET study of $5 \mathrm{HT}(2 \mathrm{~A})$ serotonin and $\mathrm{D}(2)$ dopamine dysfunction in drug-naive obsessive-compulsive disorder. Neuroimage 42, 306-314. doi: 10.1016/j.neuroimage.2008.04.233

Pine, A., Shiner, T., Seymour, B., and Dolan, R. J. (2010). Dopamine, time, and impulsivity in humans. J. Neurosci. 30, 8888-8896. doi: 10.1523/JNEUROSCI.6028-09.2010

Plavén Sigray, P., Hedman, E., Ikonen, P., Matheson, G., Forsberg, A., Djurfeldt, D., et al. (2016). Elevated levels of orbitofrontal dopamine D2-receptors in patients with social anxiety disorder. J. Cereb. Blood Flow Metab. 36, 677-678.

Plavén-Sigray, P., Hedman, E., Victorsson, P., Matheson, G., Forsberg, A., Djurfeldt, D., et al. (2017). Extrastriatal dopamine D2-receptor availability in social anxiety disorder. Eur. Neuropsychopharmacol. 27, 462-469. doi: 10.1016/j.euroneuro.2017.03.007

Reinhold, J. A., and Rickels, K. (2015). Pharmacological treatment for generalized anxiety disorder in adults: an update. Expert Opin. Pharmacother. 16, 1669-1681. doi: 10.1517/14656566.2015.1059424

Schneier, F. R., Abi-Dargham, A., Martinez, D., Slifstein, M., Hwang, D. R., Liebowitz, M. R., et al. (2009). Dopamine transporters, D2 receptors, and dopamine release in generalized social anxiety disorder. Depress. Anxiety 26, 411-418. doi: 10.1002/da.20543

Schneier, F. R., Liebowitz, M. R., Abi-Dargham, A., Zea-Ponce, Y., Lin, S. H., and Laruelle, M. (2000). Low dopamine $\mathrm{D}(2)$ receptor binding potential in social phobia. Am. J. Psychiatry 157, 457-459. doi: 10.1176/appi.ajp.157.3.457

Schneier, F. R., Martinez, D., Abi-Dargham, A., Zea-Ponce, Y., Blair Simpson, H., Liebowitz, M. R., et al. (2008). Striatal dopamine D2 receptor availability in OCD with and without comorbid social anxiety disorder: preliminary findings. Depress. Anxiety 25, 1-7. doi: 10.1002/da.20268

Schür, R. R., Draisma, L. W., Wijnen, J. P., Boks, M. P., Koevoets, M. G., Joëls, M., et al. (2016). Brain GABA levels across psychiatric disorders: a systematic literature review and meta-analysis of $1 \mathrm{H}-\mathrm{MRS}$ studies. Hum. Brain Mapp. doi: $10.1002 / \mathrm{hbm} .23244$

Spencer, A. E., Uchida, M., Kenworthy, T., Keary, C. J., and Biederman, J. (2014). Glutamatergic dysregulation in pediatric psychiatric 
disorders: a systematic review of the magnetic resonance spectroscopy literature. J. Clin. Psychiatry 75, 1226-1241. doi: 10.4088/JCP.13r 08767

Steeves, T. D., Ko, J. H., Kideckel, D. M., Rusjan, P., Houle, S., Sandor, P., et al. (2010). Extrastriatal dopaminergic dysfunction in tourette syndrome. Ann. Neurol. 67, 170-181. doi: 10.1002/ana.21809

Stein, D., Koen, N., Fineberg, N., Fontenelle, L., Matsunaga, H., Osser, D., et al. (2012). A 2012 evidence-based algorithm for the pharmacotherapy for obsessive-compulsive disorder. Curr. Psychiatry Rep. 14, 211-219. doi: 10.1007/s11920-012-0268-9

Tiihonen, J., Kuikka, J., Bergstrom, K., Lepola, U., Koponen, H., and Leinonen, E. (1997). Dopamine reuptake site densities in patients with social phobia. Am. J. Psychiatry 154, 239-242. doi: 10.1176/ajp.154.2.239

Van der Wee, N. J., Stevens, H., Hardeman, J. A., Mandl, R. C., Denys, D. A., Van Megen, H. J., et al. (2004). Enhanced dopamine transporter density in psychotropic-naive patients with obsessive-compulsive disorder shown by $\left[{ }^{123} \mathrm{I}\right] \beta$-CIT SPECT. Am. J. Psychiatry 161, 2201-2206. doi: 10.1176/appi.ajp.161.12.2201

Van der Wee, N. J., Van Veen, J. F., Stevens, H., Van Vliet, I. M., Van Rijk, P. P., and Westenberg, H. G. (2008). Increased serotonin and dopamine transporter binding in psychotropic medication-Naïve patients with generalized social anxiety disorder shown by $123 \mathrm{I}-\beta$-(4-iodophenyl)-tropane SPECT. J. Nucl. Med. 49, 757-763. doi: 10.2967/jnumed.107.045518

Wooten, D., Goer, F., Beltzer, M., Vitaliano, G., Brennan, B., Crowley, D., et al. (2015). Reduced striatal dopamine transporter binding in major depressive disorder. J. Nucl. Med. 56.

Yatham, L. N., Liddle, P. F., Shiah, I. S., Lam, R. W., Ngan, E., Scarrow, G., et al. (2002). PET study of [18F]6-fluoro-L-dopa uptake in neuroleptic and mood-stabilizer-naive first-episode nonpsychotic mania: effects of treatment with divalproex sodium. Am. J. Psychiatry 159, 768-774. doi: 10.1176/appi.ajp.159.5.768

Conflict of Interest: The authors declare that the research was conducted in the absence of any commercial or financial relationships that could be construed as a potential conflict of interest.

Copyright $\odot 2020$ Dong, Chen and Hu. This is an open-access article distributed under the terms of the Creative Commons Attribution License (CC BY). The use, distribution or reproduction in other forums is permitted, provided the original author(s) and the copyright owner(s) are credited and that the original publication in this journal is cited, in accordance with accepted academic practice. No use, distribution or reproduction is permitted which does not comply with these terms. 